\title{
Photoperiodic flowering of Arabidopsis: integrating genetic and physiological approaches to characterization of the floral stimulus
}

\author{
L. CORBESIER \& G. COUPLAND \\ Max Planck Institute for Plant Breeding Research, Carl von Linne Weg 10, D-50829 Cologne, Germany
}

\begin{abstract}
In many plants the transition from vegetative growth to flowering is controlled by environmental cues. One of these cues is day length or photoperiod, which synchronizes flowering of many species with the changing seasons. Recently, advances have been made in understanding the molecular mechanisms that confer photoperiodic control of flowering and, in particular, how inductive events occurring in the leaf, where photoperiod is perceived, are linked to floral evocation that takes place at the shoot apical meristem. We discuss recent data obtained using molecular genetic approaches on the function of regulatory proteins that control flowering time in Arabidopsis thaliana. These data are compared with the results of physiological analyses of the floral transition, which were performed in a range of species and directed towards identification of the transmitted floral singals.
\end{abstract}

Key-words: Arabidopsis; floral signals; flowering; flowering time gene; phloem; photoperiodic floral induction.

\section{INTRODUCTION}

Seasonal changes in light, temperature and rainfall have strongly influenced the evolution of life on earth. For example, many plants and animals living at latitudes above the equator often alter their behaviour or developmental programmes in response to environmental signals such as day length or temperature (Hastings \& Follet 2001). The role of day length, or photoperiod, in controlling seasonal responses was originally proposed by Tournois (1912) and Klebs (1913) at the beginning of the twentieth century, but Garner \& Allard $(1920,1923)$ were the first to show clearly that flowering and other developmental responses could be controlled by exposure to long days (LDs) or short days (SDs) depending on the plant species. They demonstrated that the duration, rather than the quantity, of light in the daily cycle was a major factor in regulating plant development and introduced the term photoperiodism, which is defined as the response to the length of the day that enables

Correspondence: George Coupland. Fax: +492215062 207; e-mail: coupland@mpiz-koeln.mpg.de living organisms to adapt to seasonal changes. Plants were then classified into photoperiodic groups based on their responses to day lengths (reviewed in Thomas \& VincePrue 1997). LD plants flower only, or most rapidly, when exposed to more than a certain number of hours of light in the daily cycle, which is referred to as the critical day length, SD plants flower only, or most rapidly, if the day length is shorter than a critical day length, and day-neutral plants flower at the same time irrespective of the photoperiodic conditions.

Later, Bünning (1936) proposed that plants might use the same time-keeping mechanism that regulates daily rhythms in leaf movements to measure day length and, thereby, control seasonal responses. Indeed, a mechanism by which plants measure the duration of a photoperiod is a prerequisite for the photoperiodic control of flowering time. Thus Bünning hypothesized that the mechanism controlling daily movements in leaves or petals, subsequently named the circadian clock, is also the basis of photoperiodic time measurement. This hypothesis was extended with the proposal that a daily rhythm that controlled the photoperiodic response and was sensitive to light at particular times of the day could explain photoperiodic time measurement (Pittendrigh \& Minis 1964). This process, referred to as the external coincidence model, has been reviewed extensively recently, and received strong support from the study of genes controlling flowering time of Arabidopsis (Yanovsky \& Kay 2003; Searle \& Coupland 2004).

Soon after the discovery of photoperiodism, day length was shown to be perceived in the leaves, although floral development occurs at the shoot apex (reviewed in Thomas \& Vince-Prue 1997). The first experiments that demonstrated this were based on exposure of different parts of the plant to distinct day lengths. Exposing only the foliage of spinach plants to LDs of $15 \mathrm{~h}$ light induced rapid flowering, while exposing the apex of the shoot to LDs while the foliage was exposed to SDs would not induce flowering (Knott 1934). This led to the conclusion that the role of the leaves in the induction of flowering in response to day length is 'in the production of some substance, or stimulus, that is transported to the growing point'. The conclusion that leaves are the source of a floral stimulus was strengthened by generating grafts between plants exposed to different conditions (see next section). 
Using experimental systems in which flowering could be strictly controlled, the flowering process was subdivided into successive steps. 'Induction' mechanisms determining flowering time occur in the leaf and precede floral 'evocation' which consists of the events occurring in the shoot apical meristem (SAM) that commit it to form flower (Evans 1969). In photoperiodic species, signals moving from the leaves to the SAM through the phloem are an important link between 'induction' and 'evocation' and movement of these substances could be timed precisely (Bernier, Kinet \& Sachs 1981a). Although transport of the floral stimulus across graft junctions was followed indirectly by its effect on flowering, its identity was difficult to establish despite extensive studies (reviewed in Bernier 1988; Bernier et al. 1993). Nevertheless, recent molecular-genetic studies in the facultative LD plant Arabidopsis thaliana have made progress in identifying genetic pathways and regulatory proteins associated with the control of flowering time (Mouradov, Cremer \& Coupland 2002; Yanovsky \& Kay 2003; Boss et al. 2004; Jack 2004; Putterill, Laurie \& Macknight 2004; Searle \& Coupland 2004). Specifically in the photoperiodic control of flowering, models were proposed in which circadian clock control of gene transcription and post-transcriptional regulation of protein stability by light can combine to confer control of a regulating pathway that mediates the induction of flowering by day length (Searle \& Coupland 2004). In this article, we focus on the later stage of photoperiodic flowering, and in particular how inductive events in the leaf are linked to floral evocation in the shoot meristem.

\section{THE FLORAL STIMULUS: INSIGHTS FROM PHYSIOLOGICAL APPROACHES}

Grafting experiments performed with several photoperiodic species clearly demonstrated that the floral stimulus is produced in the leaves. For example, in Perilla grafting of a single induced leaf onto an uninduced shoot was sufficient to induce flowering (Zeevaart 1985). The pattern and velocity of movement of the floral stimulus is similar to that of assimilates, indicating that it is transported through the phloem (King, Evans \& Wardlaw 1968; King \& Zeevaart 1973). In some species floral inhibitors, which are transmitted across graft junctions and delay flowering, have also been demonstrated (Weller et al. 1997b), whereas in other species these do not seem to occur and the inhibitory effect of uninduced leaves appears to be due to them acting as a sink for photosynthate and the contents of the phloem (Zeevaart 1976). In Perilla, once induced, a single leaf stably produces the stimulus, and can induce flowering in multiple shoots; repeated grafting of a single induced Perilla leaf sequentially triggered flowering in seven shoots over a period of $97 \mathrm{~d}$ (Zeevaart 1985).

The phenomenon of indirect induction of flowering suggests that at least in some species the floral stimulus has wider significance than triggering floral development at the shoot apex. In Xanthium strumarium, Silene armeria and Bryophyllum daigrementianum shoots induced to flower by grafting to donor shoots can themselves act as donors in subsequent grafts (Zeevaart 1976). This suggests that the floral stimulus can act in the leaves of these species to trigger its own synthesis. However, this phenomenon may not be widespread, since other species, such as Perilla, do not exhibit indirect induction of flowering. Nevertheless, grafting experiments performed with plants showing different photoperiodic responses and even originating in different genera suggest that the identity of the floral stimulus might be highly conserved. The SD plant $X$. strumarium acted as a donor of the floral stimulus when grafted to the LD plant S. armeria (Wellensiek 1970). Although, in many cases grafts between species from different genera failed this could be due to difficulties in establishing tissue connection in grafts, in genetic differences in responsiveness to the stimulus or in differences in the amount of stimulus produced by different species rather than in the identity of the stimulus (Zeevaart 1976).

Perhaps the central question addressed by physiological approaches to long-distance signalling in the floral transition is the nature of the leaf-generated signals that control the floral program at the SAM. The success of interspecies grafts led Chailakhyan (1937) to propose that the floral stimulus is a universal, unique and specific hormone called 'florigen'. Lang (1965) suggested that non-induced leaves may also produce 'antiflorigen' and, that in plants producing both florigen and antiflorigen, floral evocation is caused when the balance of these two factors at the SAM is shifted in favour of florigen. Gibberellins (GAs) were long considered to be florigen, however, GAs are florigenic in some species like Arabidopsis but failed to induce flowering in other species such as caulescent plants, which have an elongated stem at the vegetative stage (Zeevaart 1983). The limits of this florigen/antiflorigen theory are reviewed in Bernier (1988) and, despite extensive studies, these universal hormones were never isolated.

Alternative hypotheses for the identity of the long-distance signal were then proposed. Karege, Penel \& Greppin (1982) suggested that at least part of the floral stimulus exported by induced leaves could be a fast-moving electrophysiological signal. However, this does not appear compatible with the demonstration based on grafting experiments that the signal moves with assimilates in the leaves, is inhibited by sink leaves, and can take up to $72 \mathrm{~h}$ to be exported from the leaves (King \& Zeevaart 1973; Zeevaart 1976). Floral induction was proposed to be a means of modifying the source/sink relationships within the plant so that the shoot apex receives a higher concentration of assimilates, mainly sugar, than under non-inductive conditions (Sachs \& Hackett 1969). This 'Nutrient Diversion hypothesis' is based on the observation that treatments that increase photosynthate levels at the meristem accelerate flowering. These treatments included exposure to conditions that favour photosynthesis (high irradiance, high atmospheric $\mathrm{CO}_{2}$ concentration) and removal of sinks (roots, young leaves, shoot branches) that compete with the SAM for assimilates. In fact, the sucrose content of the $\mathrm{SAM}$ and/or the phloem sap reaching the SAM increases 
in several LD or SD species following floral induction (Bernier, Kinet \& Sachs 1981b; Bernier et al. 1998).

Following the observation that treatments of vegetative plants by substances such as sugars, plant growth regulators and their antagonists can induce in the SAM events specific to floral evocation, Bernier proposed the 'Multifactorial control of flowering' (Bernier 1988; Bernier et al. 1993). In this hypothesis, the floral transition occurs if all factors are present in the SAM at appropriate concentrations and times. While assimilates and hormones are generally present in most plants, some of these compounds may be absent or not present at optimal levels and the floral induction process would correct this. Nevertheless, in some species, the floral transition appears to be under the control of a single substance, such as in the LD plants Samolus parviflorus, Rudbeckia bicolor and Lolium temulentum, which can be induced to flower in SDs by treatment with $\mathrm{GA}_{3}$ (Bernier et al. 1981b; King et al. 2001).

All these theories propose that floral evocation results from the translocation of signals to the SAM in response to day lengths flowering (Kinet 1993). These signals would be transmitted through phloem sap, and to a lesser extent through the xylem. They might be identified by sap collection and comparison of the composition of the sap between vegetative and floral-induced plants. The best species to use in these studies are those in which floral induction is rapid and can be synchronized. Examples are species that can be induced to flower by a single LD, such as Sinapis alba or $L$. temulentum, or a single long night like $X$. strumarium or Pharbitis nil. In several of these physiological model plants, extensive studies of the composition of the sap were performed (reviewed in Bernier 1988; Bernier et al. 1993, 1998; Kinet 1993; Levy \& Dean 1998). Among the factors controlling the photoperiodic floral transition in $S$. alba, a caulescent plant belonging to the same family of the Brassicaceae as Arabidopsis, roles for sucrose, glutamine, cytokinins, auxin and putrescine were demonstrated, while GAs seem to play a minor role (reviewed in Bernier et al. 1993, 1998; Corbesier et al. 2004). In later sections, we focus on the photoperiodic control of flowering in Arabidopsis and try to integrate the regulatory proteins identified by molecular genetics with the leaf-generated signals proposed from physiological observations.

\section{PEA AND MAIZE AS GENETIC MODEL SYSTEMS TO APPROACH THE FLORAL STIMULUS}

Mutations or natural-genetic variation that alter floweringtime have been described in many species. Studies in pea plants were enhanced by the availability of extensive genetic stocks, and the ability to readily graft different genotypes so that the effect of this variation on long-distance signalling could be assessed (Weller et al.1997b). For example, gigas ( $g i)$ mutants flower later than wild-type plants, but their flowering is accelerated by grafting a gi shoot onto a wild-type stock (Beveridge \& Murfet 1996). This suggests that the pea $G I$ gene may be involved in the synthesis or transport of the floral stimulus. Flowering of wild-type pea plants is accelerated in response to LDs and is delayed by exposure to SDs. The gi mutant flowers later under both conditions, and often never flowers under SDs. This suggests that the floral stimulus controlled by $G I$ is not part of the response to day length, but is expressed under all environmental conditions tested.

The pea $L A T E$ FLOWERING $(L F)$ gene is proposed to encode a target of the floral stimulus at the apex of the plant; dominant alleles at this gene delay flowering and the effect is not influenced by grafting of an $L F$ shoot onto a wild-type stock (Murfet 1971,1985). LF is a homologue of the Arabidopsis gene TERMINAL FLOWER1, which was also shown to repress flowering in Arabidopsis (Foucher et al. 2003). Expression of $L F$ does not change during floral induction, suggesting that the LF protein may modulate the response to the floral stimulus at the meristem rather than be a direct target of it. In addition to the floral stimulus controlled by $G I$, there is evidence for a long-distance inhibitory signal-regulating flowering-time of pea plants. Mutations in the STERILE NODES (SNE), DIE NEUTRALIS (DNE) or PHOTOPERIOD (PPD) genes cause early flowering, and flowering of the shoots of these plants can be delayed by grafting onto a rootstock of a wild-type plant (King \& Murfet 1985; Weller, Murfet \& Reid 1997a; Weller et al. 1997b). Plants in which these genes are mutated are almost day-length insensitive, flowering at the same time under both LDs and SDs, indicating that the photoperiod response is largely caused by production of an inhibitor under SDs. These experiments suggested a model in which the timing of the transition to flowering at the apex of pea plants is determined by a balance between longdistance promotive and inhibitory signals, so that, when the ratio of stimulus to inhibitor exceeds a certain level, flowering occurs (Weller et al. 1997b).

Analysis of the INDETERMINATE (ID) gene of maize provided the first molecular information on a gene that appear to regulate the floral stimulus. Mutations in ID dramatically delay the transition to flowering, so that many more leaves are formed than in wild-type plants (Colasanti, Yuan \& Sundaresan 1998). Eventually id mutants do flower, but the reproductive structures develop abnormally and show vegetative characteristics. ID mRNA which encodes a putative transcriptional regulator was detected in young, immature leaves, but not in the SAM or in mature leaves. The expression of $I D$ in the leaves, but not the SAM, indicated that it acts to regulate long-distance signals that influence the transition to flowering of the meristem. The expression of $I D$ appears to occur in sink leaves, which receive nutrients from photosynthetically active source tissues, and not to be expressed in source leaves (Colasanti \& Sundaresan 2000). This observation led to the suggestion that ID may not promote the production of the floral stimulus, but rather acts in the developing leaves to regulate its flow. However, the mechanism by which ID regulates flowering requires further knowledge of the identity and function of the genes whose expression it regulates. 


\section{MOLECULAR-GENETICS IN ARABIDOPSIS: IDENTIFICATION OF A REGULATORY HIERARCHY THAT CONTROLS FLOWERING}

The genetic control of flowering has been most extensively studied in Arabidopsis. The behaviour of mutants exhibiting a severe delay in flowering was first described in detail by Redei (Redei 1962), and this analysis was later broadened and extended by Koornneef (Koornneef, Hanhart \& Van Der Veen 1991; Koornneef et al. 1998). More recently a large number of mutants and natural accessions showing either later or earlier flowering have been described (Mouradov et al. 2002).

Environmental conditions influence flowering time of Arabidopsis. As a quantitative LD- and vernalization requiring-plant, flowering of Arabidopsis is promoted by exposure to LDs and delayed under SDs, whereas vernalization treatments promote flowering (Martinez-Zapater et al.1994). In addition to these seasonal cues, less dramatic changes in ambient conditions also strongly influence flowering time. Exposure to lower temperatures $\left(16^{\circ} \mathrm{C}\right)$ delays flowering compared to the effect of growing plants at typical growth temperatures of $20-24^{\circ} \mathrm{C}$, and exposure to the high ratios of far-red to red light associated with shading conditions accelerates flowering (Blázquez, Ahn \& Weigel 2003; Cerdan \& Chory 2003).

The genes identified by mutagenesis and by allelic variation between accessions were placed in pathways based on genetic criteria and their effect on the response of flowering time to different environmental cues (Koornneef et al. 1998). The major features of this model were later confirmed by cloning of the genes and analysis of their expres- sion patterns in wild-type and mutant plants (Mouradov et al. 2002; Simpson \& Dean 2002).

Within this model four major pathways control flowering time and converge to regulate the expression of genes that integrate the information received from the different pathways (Fig. 1). One pathway controls the response to vernalization. In response to extended exposures to low temperature this pathway reduces the abundance of the mRNA encoding the MADS box transcription factor FLOWERING LOCUS C (FLC), which is a potent repressor of flowering (Michaels \& Amasino 1999; Sheldon et al. 1999). Therefore, vernalization accelerates flowering by reducing FLC expression. Mutations in the second pathway, the autonomous pathway, delay flowering under both LDs and SDs, and cause an increase in FLC mRNA levels (reviewed in Boss et al. 2004). This second genetic pathway also regulates $F L C$ expression but independently of vernalization so that the high FLC mRNA levels observed in these mutants can be corrected by vernalization. Mutants affected in this pathway also show an altered flowering time in response to ambient temperatures (Blázquez et al.2003). The autonomous pathway appears to represent protein complexes involved in histone modification and RNA processing (He, Michaels \& Amasino 2003; Simpson et al. 2003; Ausin et al. 2004), and probably also has a more general role than the regulation of FLC expression. Thirdly, application of the growth regulator $\mathrm{GA}_{3}$ promotes flowering of Arabidopsis, and mutations that affect genes required for GA biosynthesis delay flowering, particularly under SDs (Wilson, Heckman \& Somerville 1992). Finally, the photoperiodic pathway controls the response to day length, and specifically promotes flowering in response to

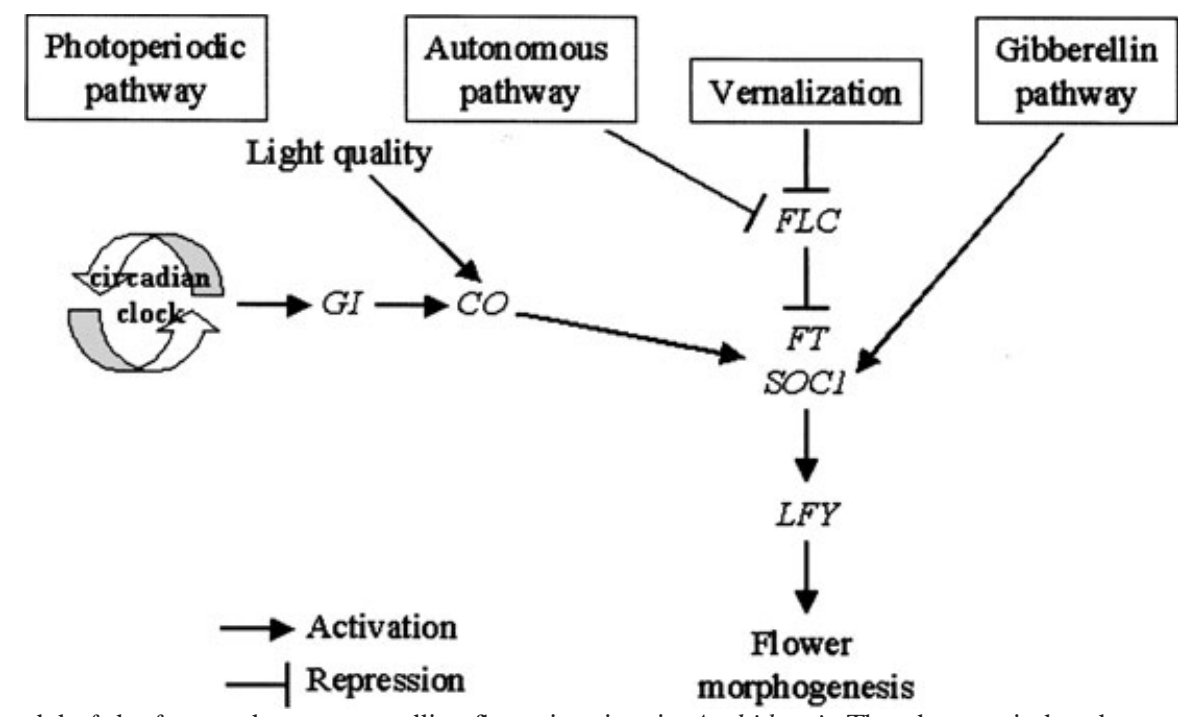

Figure 1. Simple model of the four pathways controlling flowering time in Arabidopsis. The photoperiod pathway promotes flowering specifically under LDs. The transcription of the $G I$ and $C O$ genes is regulated by the circadian clock, whereas the light quality regulates CO protein abundance. The autonomous pathway negatively regulates the abundance of the mRNA of the floral repressor FLC. FLC mRNA are also repressed by vernalization but independently of the autonomous pathway. Finally gibberellin promotes flowering of $A$ rabidopsis, particularly under SDs. All four pathways appear to converge on the transcriptional regulation of the floral integrators genes FT and SOC1 which promote $L F Y$, a gene required to confer floral identity on developing floral primordia. The data underlying this model are described in detail in the text. 
LDs (Yanovsky \& Kay 2003; Hayama \& Coupland 2003; Searle \& Coupland 2004). Mutations in this pathway can either delay flowering under LDs or accelerate flowering under SDs. The last gene that is specifically involved in this pathway is CONSTANS (CO), which encodes a zinc finger protein that promotes transcription of downstream flowering-time genes (Putterill et al. 1995; Robson et al. 2001). This photoperiodic pathway probably also plays a role in the effect of light quality on flowering, because high ratios of far-red to red light promote flowering and stabilize the CO protein (Valverde et al. 2004), although the flowering response to light quality also involves a $\mathrm{CO}$-independent pathway (Cerdan \& Chory 2003).

These distinct genetic pathways finally converge to regulate the expression of a small group of downstream genes, sometimes described as floral integrators (Mouradov et al. 2002; Simpson \& Dean 2002). This group includes two genes that promote flowering, FLOWERING LOCUS T (FT) and SUPPRESSOR OF OVEREXPRESSION OF CO 1 (SOC1) and LEAFY, a gene encoding a transcription factor required to confer floral identity on developing floral primordia. FT encodes a protein with similarity to RAF kinase inhibitors of animals (Kardailsky etal. 1999; Kobayashi et al. 1999) whereas SOC1 encodes a MADS box transcription factor (Borner et al. 2000; Lee et al. 2000; Samach et al. 2000). Mutations in each of these genes delay flowering, whereas their overexpression from the viral CaMV $35 \mathrm{~S}$ promoter causes extreme early flowering. The expression of SOC1 and FT is increased by $\mathrm{CO}$ and reduced by FLC, indicating that they are downstream of the point of convergence of the vernalization and photoperiod pathways (Samach et al. 2000; Hepworth et al. 2002). Furthermore, the expression of SOC1 is increased by treating plants with GA, suggesting that it acts downstream of all three pathways (Moon et al. 2003).

\section{POSITIONING THE FLORAL STIMULUS WITHIN THE REGULATORY NETWORK}

A major problem in the genetic analysis of the floral transition has been in elucidating in which tissues of the plant the expression of particular flowering-time genes must occur to enable floral induction to proceed (Périlleux \& Bernier 2002). Therefore, in most cases it has been unclear whether specific pathways regulate the function of longdistance signals expressed in the leaves or respond to these signals in the meristem. Simply analysing the spatial pattern of expression of these genes did not help to address this problem, because many flowering-time genes are expressed broadly.

For example, classical physiological experiments suggested that vernalization acts in the meristem to promote flowering (Michaels \& Amasino 2000). Initial observations were based on exposing only the leaves or only the apices of celery plants to vernalization treatments, and demonstrating that vernalization of the meristem was sufficient to induce flowering. The vernalization pathway is therefore likely to act in the meristem to reduce FLC expression and thereby induce flowering, and this may also be true for the autonomous pathway. Consistent with vernalization acting in the meristem, FLC is expressed specifically in the shoot and root meristems in young seedlings, although in older plants it is also expressed in expanded leaves (Michaels \& Amasino 2000; Sheldon et al. 2002; Noh \& Amasino 2003; Bastow et al. 2004).

Concerning the photoperiodic induction of flowering, existence of the floral stimulus was originally demonstrated by inducing flowering with appropriate day lengths and grafting experiments (see Introduction and next section). Therefore the photoperiod pathway of Arabidopsis might be expected to include long-distance signalling components analogous to the floral stimulus. A molecular hierarchy within the photoperiod pathway has been defined. Two flowering-time genes specific to this pathway are GIGANTEA $(G I)$ and CO. The GI gene encodes a large protein of 1173 amino acids that is present in the nucleus and is highly conserved among the angiosperms but has no animal homologues (Fowler et al. 1999; Park et al. 1999). The biochemical function of GI is unknown, but gi mutations cause severe late flowering (Redei 1962), whereas overexpression of GI causes early flowering (Wright \& Coupland unpublished). GI regulates flowering time at least in part by the regulation of $C O$ mRNA abundance; $g i$ mutants contain less $C O$ mRNA (Suarez-Lopez et al. 2001) while $G I$ overexpressors show higher $C O$ mRNA abundance. The abundance of $G I$ and $C O$ mRNAs is circadian clock regulated. Under LDs of $16 \mathrm{~h}$ light, in which these genes promote early flowering, GI mRNA abundance peaks around $10-12 \mathrm{~h}$ after dawn, whereas $C O$ mRNA abundance rises around $12 \mathrm{~h}$ after dawn and stays high throughout the night until the following dawn (Fowler et al. 1999; Park et al. 1999; Suarez-Lopez et al. 2001). CO mRNA abundance is therefore high when plants are exposed to light at the end of a LD. $C O$ expression is also regulated at the post-transcriptional level, so that the cryptochrome and phytochrome A photoreceptors act at the end of the day to stabilize the $\mathrm{CO}$ protein (Valverde et al. 2004), whereas in darkness the protein is rapidly degraded, probably as a consequence of being ubiquitinated. Under SDs the $C O$ mRNA is only expressed in the dark, and so the protein would be predicted never to accumulate. In agreement with these data, in wild-type plants $F T$ is activated by $\mathrm{CO}$ under LDs, but not under SDs (Suarez-Lopez et al. 2001; Yanovsky \& Kay 2002). Therefore, the combination of circadian clock mediated regulation of $C O$ mRNA abundance, and stabilization of $\mathrm{CO}$ protein by exposure to light can explain why CO promotes FT expression and, thus, flowering only under LDs.

The observation that $\mathrm{CO}$ is a major part of the molecular mechanism by which Arabidopsis discriminates between LDs and SDs suggests that CO may act in the leaf to regulate the transition to flowering at the apex. The $C O$ mRNA is present at very low abundance, but is expressed widely. In situ hybridizations and reverse transcriptase 
(RT)-polymerase chain reaction (PCR) detected the $\mathrm{CO}$ mRNA in the meristem, young leaf primordia and whole seedling (Putterill et al. 1995; Simon, Igeno \& Coupland 1996). A more refined expression pattern was identified using fusions of the $C O$ promoter to the $G U S$ marker gene (Takada \& Goto 2003; An et al. 2004). In CO:GUS plants, GUS expression was most strongly detected in the phloem of cotyledons, leaves and stems, but also in the protoxylem, young leaves and meristem.

Several recent observations suggest that $\mathrm{CO}$ acts in the vascular tissue and not the meristem to promote flowering. In wild-type plants, the $\mathrm{CO}$ target gene, $F T$, is expressed in the phloem, as detected using FT::GUS reporter constructs. Furthermore, FT expression is increased in the early flowering terminal flower 2 ( $t f 2)$ mutant, and in particular is expressed at higher levels in the vascular tissue, suggesting that CO may activate its target gene in these tissues (Takada \& Goto 2003). Consistent with this conclusion, FT expression was reduced in $t f 2$ co2 plants compared to tfl 2 mutants. Ayre \& Turgeon (2004) showed recently that specifically triggering the expression of $C O$ in the companion cells of the minor veins of the phloem of the mature leaves, using the promoter of a gene from melon encoding galactinol synthase (GAS) complemented the col mutation. Independently, An et al. (2004), using the phloem companion cell-specific promoter of the SUCROSE TRANSPORTER 2 (SUC2) gene of Arabidopsis, obtained similar results and showed that expression of $C O$ from meristem-specific promoters had no effect on flowering. Therefore, $C O$ appears to act specifically in the vascular tissue to regulate the synthesis or transport of a long-distance signal that initiates floral development at the apex.

Some proteins can move through the phloem from source to sink tissues, but $\mathrm{CO}$ protein itself is unlikely to be the long-distance signal. The SUC2 promoter is specific to the companion cells of the phloem of source tissues, mature leaves and stem, and expression of GUS enzyme from this promoter produced staining specifically in the vasculature of these tissues (Truernit \& Sauer 1995). In contrast, expression of GFP from the same promoter produced fluorescence both in source and sink leaves, indicating that GFP is downloaded from the companion cells into the phloem sieve elements and transported to sink leaves (Imlau, Truernit \& Sauer 1999). However, CO is approximately $20 \mathrm{kDa}$ larger than GFP and expression of GFP:CO from the SUC2 promoter complemented the co2 mutation, but GFP fluorescence was only detected in the vascular tissue and not in the meristem or leaf epidermal cells (An et al. 2004). After grafting of col mutant scions onto GAS::CO Columbia stocks, Ayre \& Turgeon (2004) were not able to detect $C O$ mRNA by PCR in the col scions. This, together with the observation that $\mathrm{CO}$ does not promote flowering when expressed in the meristem, suggests that $\mathrm{CO}$ acts in the phloem of the mature leaves to promote flowering and is not transported to other cells.

The mechanism by which $\mathrm{CO}$ acts to promote flowering in the phloem partially involves the FT gene. FT mRNA abundance was increased in the phloem of $S U C 2:: C O$ plants, and $f t$ mutations strongly suppressed the early flowering of $S U C 2:: C O$ (An et al. 2004). Furthermore, expression of $F T$ in the phloem from the SUC2 promoter complemented the co mutation. However, in contrast to $\mathrm{CO}$, FT promoted flowering when expressed in the meristem and the epidermal layer, as well as the phloem (An et al. 2004). No data are available so far on the movement of the FT protein between cells. However, FT is a small protein of $23 \mathrm{kDa}$ (Kardailsky et al. 1999; Kobayashi et al. 1999) and is therefore smaller than GFP, suggesting that it may be able to move freely between cells. Furthermore, the observation that $F T$ can promote flowering when expressed in the meristem is consistent with the idea that the protein could move from the phloem to the meristem where it acts to promote flower development. However, these data could also be explained if FT can act in almost any cell type to trigger the synthesis of a small molecule that induces flowering and is able to move freely between cells.

The biochemical function of FT is unknown. It is a member of a small protein family in Arabidopsis and shares homology with characterized proteins in other species. These proteins are referred to as CETS, after CENTRORADIALIS (CEN) of Antirrhinum majus, TERMINAL FLOWER 1 (TFL1) of Arabidopsis and SELF PRUNING (SP) of tomato (Bradley et al. 1997; Pnueli et al. 1998; Kardailsky et al. 1999; Kobayashi et al. 1999). CETS proteins share homology to RAF kinase inhibitor proteins of mammals (Kardailsky et al. 1999; Pnueli et al. 2001), and the crystal structure of CEN is similar to that of RAF kinase inhibitors (Banfield \& Brady 2000). In the yeast two-hybrid system, the interaction of SP with a NIMA-like kinase, bZIP transcription factors and a 14-3-3 protein led to the suggestion that CETS proteins act as adapters in a variety of signalling pathways (Pnueli et al. 2001). How these interactions relate to the role of FT in promoting flowering is not known. Combining $f t$ mutations with mutations affecting flower development identified a strong genetic interaction between $f t$ and mutations in the floral organ identity gene LEAFY ( $L F Y$ ) (Ruiz-Garcia et al. 1997). The ft lfy double mutant failed to produce any mature floral organs, and resembled a lfy apetalal (ap1) double mutant. This indicates that the role of FT in promoting flowering might involve the activation of $A P 1$, which is expressed exclusively at the meristem in floral primordia. One possibility is that in wild-type plants, FT mRNA is also expressed in the meristem, although so far this has not been detected. Alternatively, FT might activate a long-distance signal in the phloem that leads to $A P 1$ activation in the meristem, or FT protein either alone or together with a physiologically defined component of the floral stimulus such as sucrose might move to the meristem where it activates $A P 1$. The involvement of sucrose is supported by suggestions that it is required together with GA to activate $L F Y$ expression (Blázquez et al. 1998). Similarly, Roldan et al. (1999) showed that addition of sucrose to the growing medium of 
co3 mutant grown either in light or in darkness complemented the co mutation whereas this sugar treatment was insufficient to correct the $\mathrm{ft}-1$ mutation.

The small size of the FT protein suggests that it may move from the phloem to the meristem and directly trigger changes in gene expression. Symplastic downloading of proteins from the sieve elements into the sink tissues of the apex through plasmodesmata has been proposed (RuizMedrano, Xoconostle-Cazares \& Lucas 2001), suggesting that FT may move directly by this mechanism into apical cells and induce flowering. Furthermore, the size exclusion limit or selectivity of plasmodesmata that allow downloading from the sieve elements into the meristem have been shown to change around the time of flowering (Gisel et al. 2002) as well as their frequency (Ormenese et al. 2000), suggesting that this might be an important regulatory step. If FT does move from the companion cells of the leaf to the meristem, nothing is known of the mechanisms underlying its export from the leaf and import to the crucial cells of the meristem.

\section{IDENTIFICATION OF THE FLORAL STIMULUS IN ARABIDOPSIS: INTEGRATING MOLECULAR- GENETIC AND PHYSIOLOGICAL APPROACHES}

At present, a divide exists between the work performed in physiological model species, in which no regulating network has been described, and work on Arabidopsis in which very few studies have explored the flowering behaviour of mutants and transgenics affected in metabolism, transport or transduction of putative floral signals, such as sucrose and growth regulators. Arabidopsis, as a small rosette plant, is not ideal for biochemical analyses. In addition, although it is a LD plant, some of the accessions commonly used in the laboratories flower very rapidly, even under SDs, rendering difficult the establishment of a growing system allowing the control and the synchronization of the floral transition.

So far, only the Columbia ecotype has been used successfully in this respect. Corbesier et al. (1996) designed a growing system in which, after a period of vegetative growth in non-inductive $8 \mathrm{~h}$ SDs, Columbia plants were synchronously induced to flower by exposure to a single LD of $22 \mathrm{~h}$ or to a single $8 \mathrm{~h}$ SD shifted $10 \mathrm{~h}$ later within a $24 \mathrm{~h}$ cycle. In these conditions, the export of the floral stimulus out of the mature leaves starts $20 \mathrm{~h}$ after the beginning of the LD and lasts for approximately $12 \mathrm{~h}$. Using grafting, Turnbull and colleagues also showed effective transmission of floral signals in Arabidopsis between shoots differing in mutations for photoperiod pathway genes or differing in photoperiod treatment (An et al. 2004; Ayre \& Turgeon 2004; Turnbull \& Justin 2004).

Carbohydrate metabolism has been related to flowering in Arabidopsis using mutants, as previously shown for $S$. alba using physiological approaches (Bernier et al. 1993). Eimert et al. (1995) observed that the late-flowering gi mutant assigned to the photoperiodic pathway accumulates excess starch in the leaves and the stem during the photo- period. They also showed that the carbohydrate accumulation mutant1 (cam1), an Arabidopsis mutant accumulating starch at higher levels than the wild type just before the onset of flowering, was late-flowering in continuous light and in SD conditions. However, the accumulation of starch per se does not seem to be the direct cause of the lateflowering phenotype in these mutants since the floweringtime defect conferred by gi and caml was not rescued by crossing them with mutants lacking starch.

Studies with the phosphoglucomutase1 (pgm1) mutant, which is deficient in starch biosynthesis (Caspar, Huber \& Somerville 1985), show that sucrose plays a critical role in the floral transition (Corbesier, Lejeune \& Bernier 1998). A strong increase in the export of sucrose from mature leaves could be observed transiently between 16 and $24 \mathrm{~h}$ after the start of the inductive LD. On exposure of the pgm1 mutant to the displaced SD, in which the time of exposure to light but not the duration of light is changed, flowering did not occur in the absence of increased export of sucrose. In this system, both photosynthesis and starch mobilization are important for flowering to occur similar to what has been previously shown for S. alba (Bernier et al. 1993, 1998). Yu et al. (2000), using another Arabidopsis mutant deficient in starch synthesis also described the important role played by sugar metabolism in floral initiation. Interestingly, addition of sucrose to the growing medium of $\operatorname{co} 3$ mutants grown either in light or in darkness complemented the co mutation while this treatment was not effective with the ft-1 mutant (Roldan et al. 1999; Ohto et al. 2001). These results suggest that sucrose might act downstream of $\mathrm{CO}$ in the photoperiodic pathway, but upstream or in parallel to FT. A careful analysis of sugar metabolism and sucrose transport in these mutants may also help in understanding the potential link between $C O$, sucrose and $F T$. Sucrose may also be involved in the transcriptional regulation of $L F Y$. Addition of $1 \%$ sucrose in the growing medium of transgenic $L F Y:: G U S$ plants enhanced the expression of the transgene in vegetative plants (Blázquez et al. 1998). This increase was potentiated by simultaneous incubation with $\mathrm{GA}_{3}$, although incubation with $\mathrm{GA}_{3}$ alone did not have a noticeable effect.

Changes in the amino acid content of the phloem sap of Arabidopsis at floral transition have not really been investigated, even although amino acids are the second most prevalent compound (behind carbohydrates) found in this sap (Peoples \& Gifford 1990; Lam et al. 1995). In Arabidopsis, Corbesier et al. (2001) showed that both LD and displaced SD inductive treatments were correlated with an increased export of glutamine or asparagine in the phloem sap. This export occurs at the same time as that of sucrose and at a time compatible with the export of the floral stimulus out of the leaves. In parallel, the $\mathrm{C} / \mathrm{N}$ ratio of the phloem sap, mainly the sucrose/glutamine ratio, increases suggesting that the relative availability of $\mathrm{C}$ and $\mathrm{N}$ at the level of the SAM could be of critical importance (Corbesier, Bernier \& Périlleux 2002 and unpublished results). However, although the comparative analysis of $S$. alba and Arabidopsis gave consistent results, whether the changes 
observed are causally related to flowering cannot be asserted.

Apart from GAs (reviewed in Mouradov et al. 2002), little is known concerning the roles of growth regulators in flowering of Arabidopsis. Exogenous applications of cytokinins accelerated flowering in various ecotypes (Michniewicz \& Kamienska 1965; Besnard-Wibaut 1981; He \& Loh 2002). In the Columbia ecotype, exogenous application of cytokinin accelerates flowering, but only when the light irradiance was low, supporting the idea that the cytokinin effect is dependent on the carbohydrate level (Dennis et al. 1996). Moreover, high endogenous levels of cytokinins are associated with early flowering in Columbia plants treated with triacontanol, cerium and lanthanum (He \& Loh 2002), as well as in the ampl mutant (Chaudhury et al. 1993; Nogué et al. 2000). However, early flowering of ampl may not be a direct consequence of cytokinin levels as the AMP1 gene encodes a putative glutamate carboxypeptidase that is not predicted to be directly involved in cytokinin biosynthesis (Helliwell et al. 2001). Nevertheless, the amp1 mutation rescued the late-flowering phenotype of the gi mutant, which regulates the photoperiodic pathway (Dennis et al. 1996), formally suggesting that cytokinins could act downstream of $G I$.

Cytokinins of the isopentenyladenine family increase in abundance in both the mature leaves and the phloem sap of Arabidopsis leaves at the end of the inductive LD and during the following SD (Corbesier et al. 2003). Although these changes occurred later than those of sucrose, they were detected at the time that the floral stimulus moves out of the leaves (Corbesier et al. 1996). Immunolocalization approaches also demonstrated that the SAM of LDinduced Arabidopsis plants contained more isopentenyladenine and zeatin than vegetative SD controls. These observations are coincident with the observed increase in the rate of cell division in the SAM during flowering (Jacqmard, Gadisseur \& Bernier 2003) and with the essential role played by this class of growth regulators in the control of cell proliferation (Francis \& Sorrell 2001; Stals \& Inzé 2001). A similar situation was reported in $S$. alba apices (Jacqmard et al.2002). Endogenous cytokinins might therefore play a role in the control of cell division during the floral transition in Arabidopsis and act as a component of the floral stimulus of leaf origin. However, so far, little is known about their action on flowering gene expression in Arabidopsis, although in S. alba cytokinins activate expression of SaMADSA, the ortholog of Arabidopsis SOC1 (Bonhomme et al. 2000).

Recent experiments support a role for salicylic acid (SA) in control of flowering of Arabidopsis (Martinez et al. 2004) as proposed in the past for other species (Cleland 1974; Cleland \& Ajami 1974; Goto 1981). SA is involved in stressinduced early flowering in Arabidopsis, and might interact with the autonomous pathway through an FCA-independent branch and the photoperiod-dependent pathway through a CO-independent process. In late-flowering SAdeficient Arabidopsis plants, the levels of CO, FT and SOC1 transcripts decreased to around $50 \%$ of those found in wild-type plants under LDs (Martinez et al. 2004). In contrast, in SD-grown plants, only the level of FT was decreased while $C O$ transcript abundance was increased and SOC1 mRNA levels remained unchanged. Plants carrying the col mutation and the nah $G$ transgene, which prevents accumulation of SA because it promotes rapid and efficient conversion of SA to catechol (Delaney et al.1994), resulted in plants flowering later than the col mutant in LDs and this late flowering could be corrected by application of SA. The precise role of SA remains however, to be determined.

Further studies may establish more precise relationships between putative floral signals such as sucrose, cytokinins and SA, and the established hierarchy of regulating proteins that control flowering from the phloem.

\section{MICRO-RNAS, NEW CANDIDATES FOR THE FLORAL STIMULUS?}

Recently, small RNAs have emerged as another candidate for a component of the floral stimulus. In recent years, evidence has accumulated that micro-RNAs (miRNAs) play a major role in the control of eukaryotic gene expression. miRNAs and related small interfering RNAs are 21to 25-nucleotides non-coding RNA molecules that regulate the translation and/or stability of protein-coding mRNAs (Reinhart etal. 2002; Carrington \& Ambros 2003). Recently, several miRNAs have been found to play specific roles in plant development, including the regulation of flowering time and floral organ identity (Aukerman \& Sakai 2003; Chen 2004).

Using an activation-tagging approach, Aukerman \& Sakai (2003) and Chen (2004) found that miR172 (Park et al.2002), which is normally expressed in a temporal manner, causes early flowering and disrupts the specification of floral organ identity when overexpressed in Arabidopsis. The regulatory target of that miRNA is a subfamily of APETALA2 (AP2) transcription factor mRNAs. The targets of miR172 are repressed by the miRNA, suggesting that these targets normally act as floral repressors. Indeed, overexpression of TARGET OF EAT1 (TOE1), one of the $A P 2$-like target genes, causes late flowering while double mutants for TOE1 and TOE2 are early flowering (Aukerman \& Sakai 2003). As the levels of miR172 were not altered in co or luminidependens mutants and the level of the MIR172a-2 precursor transcript was identical in LD- or SD-grown plants (Aukerman \& Sakai 2003), the positioning of miR172 within the genetic pathways that control the floral transition in Arabidopsis is difficult. Interestingly however, miR172 displays a temporal expression pattern similar to that of certain flowering-time genes, such as $F T$ and $S O C 1$, suggesting that these genes could act potentially downstream of $m i R 172$ and $A P 2$-like floral repressors (Aukerman \& Sakai 2003).

On the other hand, the analysis of global Arabidopsis gene expression allowed Schmid et al. (2003) to identify a large group of potential floral repressors that are downregulated upon floral induction by LDs. Among these, 


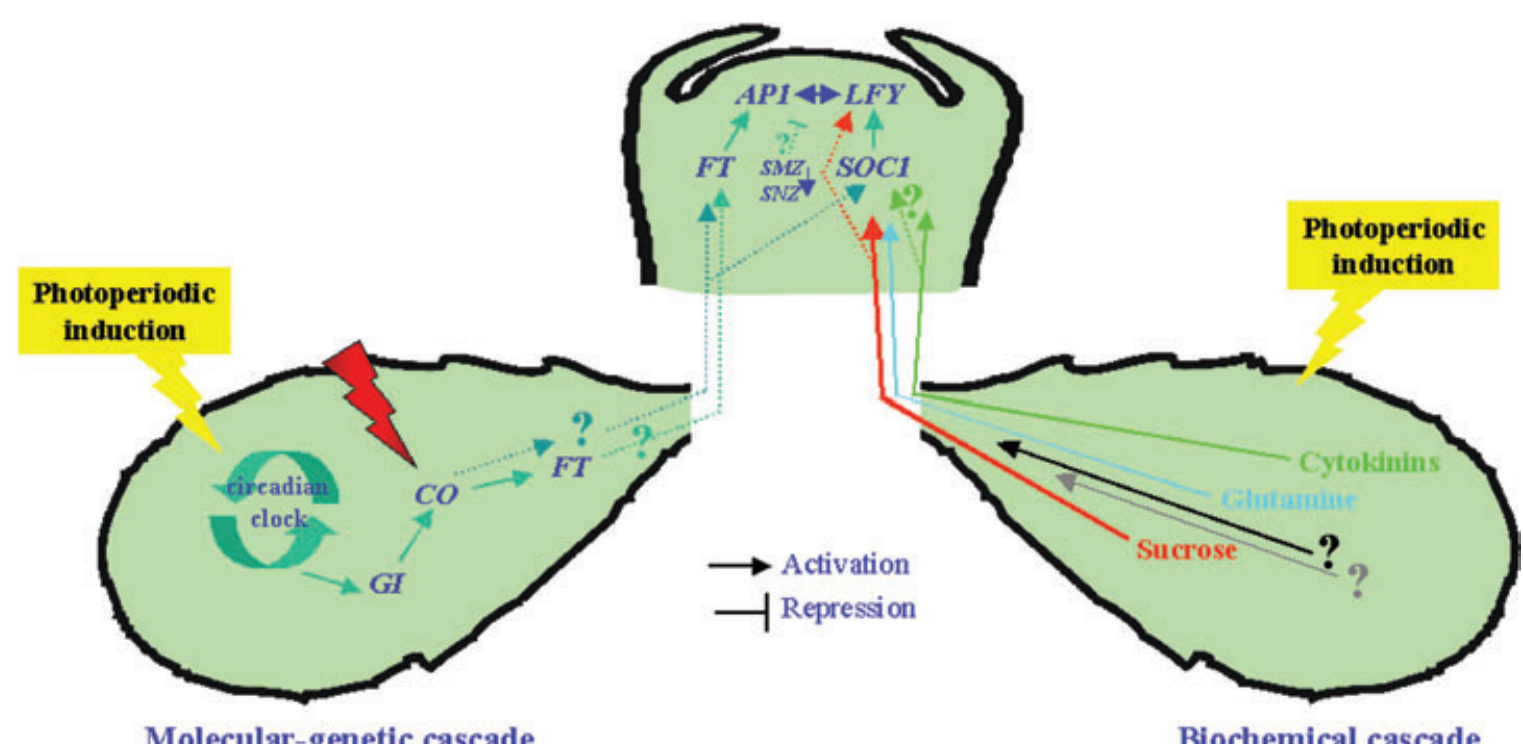

Figure 2. Signalling cascades regulating flowering time by photoperiod in Arabidopsis. On the left, the molecular-genetic cascade involving transcriptional activation of genes such as $C O$ and $F T$ in the leaves through the circadian clock in response to LDs. The result of this gene activation is then transmitted to the SAM where floral morphogenesis takes place. How this signal is transmitted is unknown, but might involve movement of FT protein. On the right, the biochemical cascade in which the LD induction causes increased export of sucrose, glutamine and cytokinins from the leaves towards the SAM. Both the molecular and biochemical changes occurring in the leaves in response to LDs activate a second molecular cascade at the SAM. This leads to the reduction of SMZ and SNZ expression, and to activation of SOC1 expression and finally to the activation of $L F Y$ and $A P 1$, which induce floral morphogenesis in the SAM. The major unresolved question is how these molecular and biochemical changes interact with each other, both in the leaves and in the SAM. The data underlying this figure are described in detail in the text.

SCHLAFMÜTZE (SMZ) and SCHNARCHZAPFEN (SNZ) are two other $A P 2$-like genes and potential targets for miR172. Although SMZ and SNZ have only a single AP2 domain, phylogenetic analysis showed that they both fall within the same clade as the one defined by TOE1 and TOE2 (Schmid et al. 2003). SMZ and $S N Z$ were repressed upon photoperiod change in Col and Ler wild type and lfy mutants but not in $c o$ and $f t$ mutants, suggesting that these other $A P 2$-like genes function as floral repressors and act downstream of $C O$ and $F T$ but upstream of $L F Y$. In their conditions, they found that the MIR172a-2 precursor was up-regulated after floral induction in a $C O$ - and $F T$ dependent manner. Although that seemed to occur at the shoot apex, and may be an indirect effect of $C O$ and $F T$ function in the phloem.

The miR159 is also involved in the control of flowering time in Arabidopsis (Achard et al. 2004). The GA pathway promotes flowering in SDs via a GAMYB-dependent (primarily MYB33) activation of $L F Y$ (Blázquez et al. 1998; Blázquez \& Weigel 2000; Gocal et al. 2001) and, consistent with these ideas, Achard et al. (2004) found that transgenic overexpression of miR159a resulted in a reduction of the levels of $M Y B 33$ and $L F Y$ transcripts, and a specific delay in flowering in SDs. The level of $m i R 159$ was also positively regulated by GA and negatively regulated by GAI and RGA proteins, suggesting some complexity in the regulation of miR159 level.

Although the miRNAs found to play a role in the control of the floral transition have not yet been assigned definitively to a certain genetic pathway, miRNAs, as well as mRNAs and proteins, can move within the phloem sap and between cells allowing them to be considered as potentially a new class of floral signal (Ding, Itaya \& Qi 2003). In this respect, Yoo et al. (2004) show that small RNA molecules can enter and move through the phloem of several plant species such as Cucurbita maxima, Cucumis sativus, Lupinus albus, Ricinus communis and Yucca filamentosa. They also found the ortholog of the Arabidopsis miR159 in cucurbit phloem sap. In addition, a novel protein, Cucurbita maxima PHLOEM SMALL RNA BINDING PROTEIN1, that seems to play a role in trafficking of small RNA through phloem and facilitating the movement of small RNA across plasmodesmata, was identified. Finally, heterografting experiments showed that these small RNAs can enter and move with the phloem translocation stream (Yoo et al.2004). Analysis of the miRNAs present in the phloem sap of Arabidopsis following the photoperiodic induction of flowering may assess the importance of these molecules as part of the floral stimulus.

\section{PROSPECTS}

One of the major goals in understanding the photoperiodic control of flowering is to link the activation of floweringtime genes expressed in the leaf with the export of the floral signal and the role played by these signals at the SAM. 
Recent progress has begun to integrate the data derived from the molecular-genetic approach on the regulatory proteins controlling flowering with those based on the physiological analysis of the floral transition and on grafting experiments (Fig. 2). However the nature of the transmitted signal and the full complement of genes activated in the phloem companion cells by regulatory proteins such as $\mathrm{CO}$ still remains unclear. Nevertheless, the rate of current progress suggests that a more complete integration of the information derived from the physiological and the genetic approaches may soon be possible.

\section{ACKNOWLEDGMENTS}

We thank Fréderic Cremer for help and discussion and Jo Putterill for critical reading of the manuscript.

\section{REFERENCES}

Achard P., Herr A., Baulcombe D.C. \& Harberd N.P. (2004) Modulation of floral development by a gibberellin-regulated microRNA. Development 131, 3357-3365.

An H., Roussot C., Suarez-Lopez P., Corbesier L., Vincent C., Pineiro M., Hepworth S., Mouradov A., Justin S., Turnbull C.G.N. \& Coupland G. (2004) CONSTANS acts in the phloem to regulate a systemic signal that induces photoperiodic flowering of Arabidopsis. Development 131, 3615-3626.

Aukerman M.J. \& Sakai H. (2003) Regulation of flowering time and floral organ identity by a microRNA and its APETALA2like target genes. Plant Cell 15, 2730-2741.

Ausin I., Alonso-Blanco C., Jarillo J.A., Ruiz-Garcia L. \& Martinez-Zapater J.M. (2004) Regulation of flowering time by FVE, a retinoblastoma-associated protein. Nature Genetics 36, 162166.

Ayre B. \& Turgeon R. (2004) Graft transmission of a floral stimulant derived from CONSTANS. Plant Physiology 135, 1-8.

Banfield M.J. \& Brady R.L. (2000) The structure of Antirrhinum centroradialis protein (CEN) suggests a role as a kinase regulator. Journal of Molecular Biology 297, 1159-1170.

Bastow R., Mylne J.S., Lister C., Lippman Z., Martienssen R.A. \& Dean C. (2004) Vernalization requires epigenetic silencing of FLC by histone methylation. Nature 427, 164-167.

Bernier G. (1988) The control of floral evocation and morphogenesis. Annual Review of Plant Physiology and Plant Molecular Biology 39, 175-219.

Bernier G., Corbesier L., Périlleux C., Havelange A. \& Lejeune P. (1998) Physiological analysis of floral transition. In Genetic and Environmental Manipulation of Horticultural Crops (eds K. Cockshull, D. Gray, G.B. Seymour \& B. Thomas), pp. 103-109. CAB International, Wallingford, UK.

Bernier G., Havelange A., Houssa C., Petitjean A. \& Lejeune P. (1993) Physiological signals that induce flowering. Plant Cell 5, 1147-1155.

Bernier G., Kinet J.-M. \& Sachs R.M. (1981a) The Physiology of Flowering, Vol. 1. CRC Press, Boca Raton, FL, USA.

Bernier G., Kinet J.-M. \& Sachs R.M. (1981b) The Physiology of Flowering, Vol. 2. CRC Press, Boca Raton, FL, USA.

Besnard-Wibaut C. (1981) Effectiveness of gibberellins and 6-benzyladenine on flowering of Arabidopsis thaliana. Physiologia Plantarum 53, 205-212.

Beveridge C.A. \& Murfet I.C. (1996) The gigas mutant in pea is deficient in the floral stimulus. Physiologia Plantarum 96, 637645 .
Blázquez M.A., Ahn J.H. \& Weigel D. (2003) A thermosensory pathway controlling flowering time in Arabidopsis thaliana. Nature Genetics 33, 168-171.

Blázquez M.A., Green R., Nilsson O., Sussman M.R. \& Weigel D. (1998) Gibberellins promote flowering of Arabidopsis by activating the $L E A F Y$ promoter. Plant Cell 10, 791-800.

Blázquez M.A. \& Weigel D. (2000) Integration of floral inductive signals in Arabidopsis. Nature 404, 889-892.

Bonhomme F., Kurz B., Melzer S., Bernier G. \& Jacqmard A. (2000) Cytokinin and gibberellin activate $\operatorname{SaMADS} A$, a gene apparently involved in regulation of the floral transition in Sinapis alba. Plant Journal 24, 103-111.

Borner R., Kampmann G., Chandler J., Gleissner R., Wisman E., Apel K. \& Melzer S. (2000) A MADS domain gene involved in the transition to flowering in Arabidopsis. Plant Journal 24, 591599.

Boss P.K., Bastow R.M., Mylne J.S. \& Dean C. (2004) Multiple pathways in the decision to flower: enabling, promoting, and resetting. Plant Cell 16, S18-S31.

Bradley D., Ratcliffe O., Vincent C., Carpenter R. \& Coen E. (1997) Inflorescence commitment and architecture in Arabidopsis. Science 275, 80-83.

Bünning E. (1936) Die endogene Tagesrhythmik als Grundlage der photoperiodischen Reaktion. Ber Deutsch Botan Gesellschaft 54, 590-607.

Carrington J.C. \& Ambros V. (2003) Role of MicroRNAs in plant and animal development. Science 301, 336-338.

Caspar T., Huber S.C. \& Somerville C. (1985) Alterations in growth, photosynthesis and respiration in a starchless mutant of Arabidopsis thaliana (L.) deficient in chloroplast phosphoglucomutase activity. Plant Physiology 79, 11-17.

Cerdan P.D. \& Chory J. (2003) Regulation of flowering time by light quality. Nature 423, 881-885.

Chailakhyan M.K. (1937) Concerning the hormonal nature of plant development processes. Doklady Akad Nauk SSSR 16, 227-230.

Chaudhury A.M., Letham S., Craig S. \& Dennis E.S. (1993) amp1 - a mutant with high cytokinin levels and altered embryonic pattern, faster vegetative growth, constitutive photomorphogenesis and precocious flowering. Plant Journal 4, 907-916.

Chen X. (2004) A microRNA as a translational repressor of APETALA2. Arabidopsis flower development. Science 303, 2022-2025.

Cleland C.F. (1974) Isolation of flower-inducing and flower-inhibitory factors from aphid honeydew. Plant Physiology 54, 889903.

Cleland C.F. \& Ajami A. (1974) Identification of the flower-inducing factor isolated from aphid honeydew as being salicylic acid. Plant Physiology 54, 904-906.

Colasanti J. \& Sundaresan V. (2000) 'Florigen' enters the molecular age: long-distance signals that cause plants to flower. Trends in Biochemical Sciences 25, 236-240.

Colasanti J., Yuan Z. \& Sundaresan V. (1998) The indeterminate gene encodes a zinc finger protein and regulates a leaf-generated signal required for the transition to flowering in maize. Cell $\mathbf{9 3}$, 593-603.

Corbesier L., Bernier G. \& Périlleux C. (2002) C: N ratio increases in the phloem sap during floral transition of the long-day plants Sinapis alba and Arabidopsis thaliana. Plant and Cell Physiology 43, 684-688.

Corbesier L., Gadisseur I., Silvestre G., Jacqmard A. \& Bernier G. (1996) Design in Arabidopsis thaliana of a synchronous system of floral induction by one long day. Plant Journal 9, 947952.

Corbesier L., Havelange A., Lejeune P., Bernier G. \& Périlleux C. (2001) N content of phloem and xylem exudates during the 
transition to flowering in Sinapis alba and Arabidopsis thaliana. Plant, Cell and Environment 24, 367-375.

Corbesier L., Kustermans G., Périlleux C., Melzer S., Moritz T., Havelange A. \& Bernier G. (2004) Gibberellins and the floral transition in Sinapis alba. Physiologia Plantarum 122, 152-158.

Corbesier L., Lejeune P. \& Bernier G. (1998) The role of carbohydrates in the induction of flowering in Arabidopsis thaliana: comparison between the wild type and a starchless mutant. Planta 206, 131-137.

Corbesier L., Prinsen E., Jacqmard A., Lejeune P., Van Onckelen H., Périlleux C. \& Bernier G. (2003) Cytokinin levels in leaves, leaf exudate and shoot apical meristem of Arabidopsis thaliana during floral transition. Journal of Experimental Botany 54, 2511-2517.

Delaney T.P., Uknes S., Vernooij B., et al. (1994) A central role of salicylic acid in plant resistance. Science 266, 1247-1250.

Dennis E.S., Finnegan E.J., Bilodeau P., Chaudhury A., Genger R., Helliwell C.A., Sheldon C.C., Bagnall D.J. \& Peacock W.J. (1996) Vernalization and the initiation of flowering. Seminars in Cell and Developmental Biology 7, 441-448.

Ding B., Itaya A. \& Qi Y.J. (2003) Symplasmic protein and RNA traffic: regulatory points and regulatory factors. Current Opinion in Plant Biology 6, 596-602.

Eimert K., Wang S.-M., Lue W.-L. \& Chen J. (1995) Monogenic recessive mutations causing both late floral initiation and excess starch accumulation in Arabidopsis. Plant Cell 7, 1703-1712.

Evans L.T. (1969) The nature of flower induction. In: The Induction of Flowering - Some Case Histories. The Macmillan Company of Australia, Melbourne, Australia.

Foucher F., Morin J., Courtiade J., Cadioux S., Ellis N., Banfield M.J. \& Rameau C. (2003) DETERMINATE and LATE FLOWERING are two TERMINAL FLOWER1/CENTRORADIALIS homologs that control two distinct phases of flowering initiation and development in pea. Plant Cell 15, 2742-2754.

Fowler S., Lee K., Onouchi H., Samach A., Richardson K., Coupland G. \& Putterill J. (1999) GIGANTEA: a circadian clockcontrolled gene that regulates photoperiodic flowering in Arabidopsis and encodes a protein with several possible membranespanning domains. EMBO Journal 18, 4679-4688.

Francis D. \& Sorrell D.A. (2001) The interface between the cell cycle and plant growth regulators: a mini review. Plant Growth Regulation 33, 1-12.

Garner W.W. \& Allard H.A. (1920) Effect of the relative length of day and night and other factors of the environment on growth and reproduction in plants. Journal of Agricultural Research $\mathbf{1 8 ,}$ 553-606.

Garner W.W. \& Allard H.A. (1923) Further studies on photoperiodism, the response of plants to relative length of day and night. Journal of Agricultural Research 23, 871-920.

Gisel A., Hempel F.D., Barella S. \& Zambryski P. (2002) Leaf-toshoot apex movement of symplastic tracer is restricted coincident with flowering in Arabidopsis. Proceedings of the National Academy of Sciences of the USA 99, 1713-1717.

Gocal G.F., Sheldon C.C., Gubler F., et al. (2001) GAMYB-like genes, flowering, and gibberellin signaling in Arabidopsis. Plant Physiology 127, 1682-1693.

Goto N. (1981) Enhancement of gibberellic acid effect by 5-bromodeoxyuridine, salicylic acid and benzoic acid on the flowering of Arabidopsis thaliana. Arabidopsis Information Service 18, 157-160.

Hastings M.H. \& Follet B.K. (2001) Towards a molecular biological calendar? Journal of Biological Rhythms 15, 424-430.

Hayama R. \& Coupland G. (2003) Shedding light on the circadian clock and the photoperiodic control of flowering. Current Opinion in Plant Biology 6,13-19.

He Y.-W. \& Loh C.-S. (2002) Induction of early bolting in Arabi- dopsis thaliana by triacontanol, cerium and lanthanum is correlated with increased endogenous concentration of isopentenyl adenosine (iPAdos). Journal of Experimental Botany 53, 505512.

He Y., Michaels S.D. \& Amasino R.M. (2003) Regulation of flowering time by histone acetylation in Arabidopsis. Science 302, 1751-1754.

Helliwell C.A., Chin-Atkins A.N., Wilson I.W., Chapple R. \& Dennis E.S. (2001) The Arabidopsis AMP1 gene encodes a putative glutamate carboxypeptidase. Plant Cell 13, 2115-2125.

Hepworth S.R., Valverde F., Ravenscroft D., Mouradov A. \& Coupland G. (2002) Antagonistic regulation of flowering-time gene $S O C 1$ by CONSTANS and FLC via separate promoter motifs. EMBO Journal 21, 4327-4337.

Imlau A., Truernit E. \& Sauer N. (1999) Cell-to-cell and longdistance trafficking of the green fluorescent protein in the phloem and symplastic unloading of the protein into sink tissues. Plant Cell 11, 309-322.

Jack T. (2004) Molecular and genetic mechanisms of floral control. Plant Cell S16, 1-17.

Jacqmard A., Detry N., Dewitte W., Van Onckelen H.A. \& Bernier G. (2002) In situ localisation of cytokinins in the shoot apical meristem of Sinapis alba at floral transition. Planta 214, 970-973.

Jacqmard A., Gadisseur I. \& Bernier G. (2003) Cell division and morphological changes in the shoot apex of Arabidopsis thaliana during floral transition. Annals of Botany 91, 571-576.

Kardailsky I., Shukla V.K., Ahn J.H., Dagenais N., Christensen S.K., Nguyen J.T., Chory J., Harrison M.J. \& Weigel D. (1999) Activation tagging of the floral inducer. FT Science 286, 19621965.

Karege F., Penel C. \& Greppin H. (1982) Détection de l'état végétatif et floral de la feuille de l'épinard: emploi d'un indicateur biochimique. Archives of Science, Genève 35, 331-340.

Kinet J.M. (1993) Environmental, chemical and genetic control of flowering. Horticultural Reviews 15, 279-334.

King R.W., Evans L.T. \& Wardlaw I.F. (1968) Translocation of the floral stimulus in Pharbitis nil in relation to that of assimilates. Zeitscrift für Pflanzenphysiology 59, 377-388.

King R.W., Moritz T., Evans L.T., Junttila O. \& Herlt A.J. (2001) Long-day induction of flowering in Lolium temulentum involves sequential increases in specific gibberellins at the shoot apex. Plant Physiology 127, 624-632.

King W.M. \& Murfet I.C. (1985) Flowering in Pisum: a sixth locus DNE. Annals of Botany 56, 835-846.

King R.W. \& Zeevaart J.A.D. (1973) Floral stimulus movement in Perilla and flower inhibition caused by noninduced leaves. Plant Physiology 51, 727-738.

Klebs G. (1913) Über das Verhältnis der Aussenwelt zur Entwicklung der Pflanze. Heidelberger Academie der Wissenschaften 5, $1-47$.

Knott J.E. (1934) Effect of a localized photoperiod on spinach. Proceedings of the Society of Horticultural Science 31, 152-154.

Kobayashi Y., Kaya H., Goto K., Iwabuchi M. \& Araki T. (1999) A pair of related genes with antagonistic roles in mediating flowering signals. Science 286, 1960-1962.

Koornneef M., Alonso-Blanco C., Vries H.B.-D., Hanhart C.J. \& Peeters A.J.M. (1998) Genetic interactions among late-flowering mutants of Arabidopsis. Genetics 148, 885-892.

Koornneef M., Hanhart C.J. \& Van Der Veen J.H. (1991) A genetic and physiological analysis of late flowering mutants in Arabidopsis thaliana. Molecular and General Genetics 229, 5766.

Lam H.M., Coschigano K., Schultz C., Melo-Oliveira R., Tjaden G., Oliveira I., Ngai N., Hsieh M.H. \& Coruzzi G. (1995) Use of Arabidopsis mutants and genes to study amide amino acid biosynthesis. Plant Cell 7, 887-898. 
Lang A. (1965) Physiology of flower initiation. In Encyclopedia of Plant Physiology (ed. W. Ruhland), pp. 1380-1536. Springer Verlag, Berlin, Germany.

Lee H., Suh S.-S., Park E., Cho E., Ahn J.H., Kim S.-G., Lee J.S., Kwon Y.M. \& Lee I. (2000) The AGAMOUS-LIKE 20 MADS domain protein integrates floral inductive pathways in Arabidopsis. Genes and Development 14, 2366-2376.

Levy Y.Y. \& Dean C. (1998) The transition to flowering. Plant Cell 10, 1973-1989.

Martinez C., Pons E., Prats G. \& Leon J. (2004) Salicylic acid regulates flowering time and links defence responses and reproductive development. Plant Journal 37, 209-217.

Martinez-Zapater J.M., Coupland G., Dean C. \& Koornneef M. (1994) The transition to flowering in Arabidopsis. In Cold Spring Harbor Monograph Series; Arabidopsis (eds E.M. Meyerowitz \& C.R. Somerville), pp. 403-433. Cold Spring Harbor Laboratory Press, Plainview, New York, USA.

Michaels S.D. \& Amasino R.M. (1999) FLOWERING LOCUS C encodes a novel MADS domain protein that acts as a repressor of flowering. Plant Cell 11, 949-956.

Michaels S.D. \& Amasino R.M. (2000) Memories of winter: Vernalization and the competence to flower. Plant, Cell and Environment 23, 1145-1153.

Michniewicz M. \& Kamienska A. (1965) Flower formation induced by kinetin and vitamin $\mathrm{E}$ treatment in long-day plant (Arabidopsis thaliana) grown in short days. Naturwissenschaften 52, 623.

Moon J., Suh S.S., Lee H., Choi K.R., Hong C.B., Paek N.C., Kim S.G. \& Lee I. (2003) The SOC1 MADS-box gene integrates vernalization and gibberellin signals for flowering in Arabidopsis. Plant Journal 35, 613-623.

Mouradov A., Cremer F. \& Coupland G. (2002) Control of flowering time: interacting pathways as a basis for diversity. Plant Cell 14 (Suppl. ), S111-S130.

Murfet I.C. (1971) Flowering in Pisum: reciprocal grafts between known genotypes. Australian Journal of Biological Sciences 24, 1089-1101.

Murfet I.C. (1985) Pisum sativum. In Handbook of Flowering (ed. A.H. Halevy) Vol. 4, pp. 97-126. CRC Press, Boca Raton, FL, USA.

Nogué N., Hocart H., Letham D.S., Dennis E.S. \& Chaudhury A.M. (2000) Cytokinin synthesis is higher in the Arabidopsis amp1 mutant. Plant Growth Regulation 32, 267-273.

Noh Y.S. \& Amasino R.M. (2003) PIE1, an ISWI family gene, is required for $F L C$ activation and floral repression in Arabidopsis. Plant Cell 15, 1671-1682.

Ohto M., Onai K., Furukawa Y., Aoki E., Araki T. \& Nakamura K. (2001) Effects of sugar on vegetative development and floral transition in Arabidopsis. Plant Physiology 127, 252-261.

Ormenese S., Havelange A., Deltour R. \& Bernier G. (2000) The frequency of plasmodesmata increases early in the whole shoot apical meristem in Sinapis alba L. during floral tranisition. Planta 211, 370-375.

Park W., Li J., Song R., Messing J. \& Chen X. (2002) CARPEL FACTORY, a Dicer homolog, and HEIN1, a novel protein, act in microRNA metabolism in Arabidopsis thaliana. Current Biology 12, 1484-1495.

Park D.H., Somers D.E., Kim Y.S., Choy Y.H., Lim H.K., Soh M.S., Kim H.J., Kay S.A. \& Nam H.G. (1999) Control of circadian rhythms and photoperiodic flowering by the GIGANTEA gene. Science 285, 1579-1582.

Peoples M.B. \& Gifford R.M. (1990) Long-distance transport of nitrogen and carbon from sources to sinks in higher plants. In Plant Physiology Biochemistry and Molecular Biology (eds D.T. Dennis \& D.H. Turpin), pp. 434-447. Longman, Harlow, UK.

Périlleux C. \& Bernier G. (2002) The control of flowering: do genetical and physiological approaches converge? Annual Plant Reviews 6, 1-32.

Pittendrigh C.S. \& Minis D.H. (1964) The entrainment of circadian oscillations by light and their role as photoperiodic clocks. American Naturalist 98, 261-322.

Pnueli L., Carmel-Goren L., Hareven D., Gutfinger T., Alvarez J., Ganal M., Zamir D. \& Lifschitz E. (1998) The SELF-PRUN$I N G$ gene of tomato regulates vegetative to reproductive switching of sympodial meristems and is the ortholog of CEN and Tfl1. Development 125, 1979-1989.

Pnueli L., Gutfinger T., Hareven D., Ben-Naim O., Ron N., Adir N. \& Lifschitz E. (2001) Tomato SP-interacting proteins define a conserved signaling system that regulates shoot architecture and flowering. Plant Cell 13, 2687-2702.

Putterill J., Laurie R. \& Macknight R. (2004) It's time to flower: the genetic control of flowering time. Bioessays 26, 363-373.

Putterill J., Robson F., Lee K., Simon R. \& Coupland G. (1995) The CONSTANS gene of Arabidopsis promotes flowering and encodes a protein showing similarities to zinc finger transcription factors. Cell 80, 847-857.

Redei G.P. (1962) Supervital mutants of Arabidopsis. Genetics 47, 443-460.

Reinhart B.J., Weinstein E.G., Rhoades M.W., Bartel B.B. \& Bartel D.P. (2002) MicroRNAs in plants. Genes and Development 16, 1616-1626.

Robson F., Costa M.M.R., Hepworth S., Vizir I., Pineiro M., Reeves P.H., Putterill J. \& Coupland G. (2001) Functional importance of conserved domains in the flowering-time gene CONSTANS demonstrated by analysis of mutant alleles and transgenic plants. Plant Journal 28, 619-631.

Roldan M., Gomez-Mena C., Ruiz-Garcia L., Salinas J. \& Martinez-Zapater J.M. (1999) Sucrose availability on the aerial part of the plant promotes morphogenesis and flowering of Arabidopsis in the dark. Plant Journal 20, 581-590.

Ruiz-Garcia L., Madueno F., Wilkinson M., Haughn G., Salinas J. \& Martinez-Zapater J.M. (1997) Different roles of floweringtime genes in the activation of floral initiation genes in Arabidopsis. Plant Cell 9, 1921-1934.

Ruiz-Medrano R., Xoconostle-Cazares B. \& Lucas W.J. (2001) The phloem as a conduit for inter-organ communication. Current Opinion in Plant Biology 4, 202-209.

Sachs R.M. \& Hackett W.P. (1969) Control of vegetative and reproductive development in seed plants. Horticultural Science 4, 103-107.

Samach A., Onouchi H., Gold S.E., Ditta G.S., Schwarz-Sommer Z., Yanovsky M.F. \& Coupland G. (2000) Distinct roles of CONSTANS target genes in reproductive development of Arabidopsis. Science 288, 1613-1616.

Schmid M., Uhlenhaut N.H., Godard F., Demar M., Bressan R., Weigel D. \& Lohmann J.U. (2003) Dissection of floral induction pathways using global expression analysis. Development 130, 6001-6012.

Searle I. \& Coupland G. (2004) Induction of flowering by seasonal changes in photoperiod. EMBO Journal 23, 1217-1222.

Sheldon C.C., Burn J.E., Perez P.P., Metzger J., Edwards J.A., Peacock W.J. \& Dennis E.S. (1999) The FLF MADS box gene: a repressor of flowering in Arabidopsis regulated by vernalization and methylation. Plant Cell 11, 445-458.

Sheldon C.C., Conn A.B., Dennis E.S. \& Peacock W.J. (2002) Different regulatory regions are required for the vernalizationinduced repression of FLOWERING LOCUS C and for the epigenetic maintenance of repression. Plant Cell 14, 2527-2537.

Simon R., Igeno M.I. \& Coupland G. (1996) Activation of floral meristem identity genes in Arabidopsis. Nature 384, 59-62.

Simpson G.G. \& Dean C. (2002) Arabidopsis, the Rosetta stone of flowering time? Science 296, 285-289. 
Simpson G.G., Dijkwel P.P., Quesada V., Henderson I. \& Dean C. (2003) FY is an RNA-3' end-processing factor that interacts with FCA to control the Arabidopsis floral transition. Cell 113, 777-787.

Stals H. \& Inzé D. (2001) When plant cells decide to divide. Trends in Plant Science 6, 359-364.

Suarez-Lopez P., Wheatley K., Robson F., Onouchi H., Valverde F. \& Coupland G. (2001) CONSTANS mediates between the circadian clock and the control of flowering in Arabidopsis. Nature 410, 1116-1120.

Takada S. \& Goto K. (2003) TERMINAL FLOWER2, an Arabidopsis homolog of HETEROCHROMATIN PROTEIN1, counteracts the activation of FLOWERING LOCUS $T$ by CONSTANS in the vascular tissues of leaves to regulate flowering time. Plant Cell 15, 2856-2865.

Thomas B. \& Vince-Prue B. (1997) Photoperiodism in Plants, 2nd edn. Academic Press, San Diego, CA, USA.

Tournois J. (1912) Influence de la lumière sur la floraison du houblon japonais et du chanvre déterminées par des semis haitifs. Comptes Rendus de l'Académie Des Sciences de Paris 155, 297 300.

Truernit E. \& Sauer N. (1995) The promoter of the Arabidopsis thaliana SUC2 sucrose-H+ symporter gene directs expression of b-glucuronidase to the phloem: evidence for phloem loading and unloading by SUC2. Planta 196, 564-570.

Turnbull C.G.N. \& Justin S. (2004) Graft-transmission of floral signal in Arabidopsis. Flowering Newsletter 37, 3-10.

Valverde F., Mouradov A., Soppe W., Ravenscroft D., Samach A. \& Coupland G. (2004) Photoreceptor regulation of CONSTANS protein and the mechanism of photoperiodic flowering. Science 303, 1003-1006.

Wellensiek S.J. (1970) The floral hormones in Silene armeria L. \& Xanthium strumarium L. Zeitscrift für Pflanzenphysiology 63, 25-30.
Weller J.L., Murfet I.C. \& Reid J.B. (1997a) Pea mutants with reduced sensitivity to far-red light define an important role for phytochrome A in day-length detection. Plant Physiology 114, 1225-1236.

Weller J.L., Reid J.B., Taylor S.A. \& Murfet I.C. (1997b) The genetic control of flowering in pea. Trends in Plant Science 2, 412-418.

Wilson R.N., Heckman J.W. \& Somerville C.R. (1992) Gibberellin is required for flowering in Arabidopsis thaliana under short days. Plant Physiology 100, 403-408.

Yanovsky M.J. \& Kay S.A. (2002) Molecular basis of seasonal time measurement in Arabidopsis. Nature 419, 308-312.

Yanovsky M.J. \& Kay S.A. (2003) Living by the calendar: how plants know when to flower. Nature Reviews in Molecular Cell Biology 4, 265-275.

Yoo B.-C., Kragler F., Varkonyi-Gasic E., Haywood V., ArcherEvans S., Lee Y.M., Lough T.J. \& Lucas W.J. (2004) A systemic small RNA signaling system in plants. Plant Cell 16, 1979-2000.

Yu T.-S., Lue W.-L., Wang S.-M. \& Chen J. (2000) Mutation of Arabidopsis plastid phosphoglucose isomerase affects leaf starch synthesis and floral initiation. Plant Physiology 123, 319325.

Zeevaart J.A.D. (1976) Physiology of flower formation. Annual Review of Plant Physiology 27, 321-348.

Zeevaart J.A.D. (1983) Gibberellins and flowering. In The Biochemistry and Physiology of Gibberellins (ed. A. Crozier), pp. 333-374. Praeger, New York, USA.

Zeevaart J.A.D. (1985) Perilla. In Handbook of Flowering (ed. A.H. Halevy), pp. 239-252. CRC Press, Boca Raton, FL, USA.

Received 22 September 2004; received in revised form 20 October 2004; accepted for publication 21 October 2004 